Document downloaded from:

http://hdl.handle.net/10251/93289

This paper must be cited as:

Vacas González, S.; Alfaro Cañamás, C.; Navarro-Llopis, V.; Primo Millo, J. (2010). Mating disruption of California red scale, Aonidiella aurantii Maskell (Homoptera: Diaspididae), using biodegradable mesoporous pheromone dispensers. Pest Management Science. 66(7):745-751. doi:10.1002/ps.1937

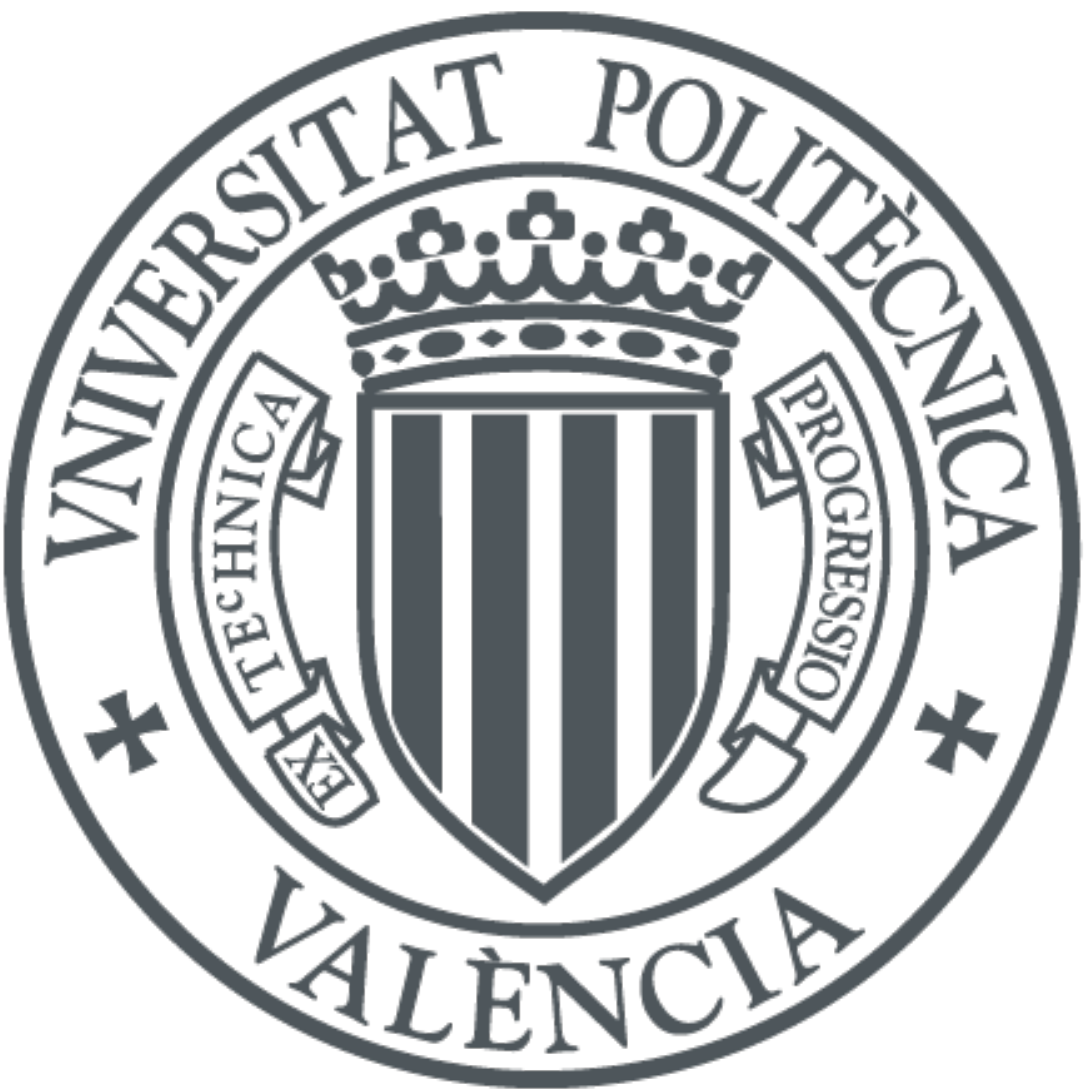

The final publication is available at

http://doi.org/10.1002/ps.1937

Copyright John Wiley \& Sons

Additional Information 


\title{
Mating disruption of California red scale, Aonidiella aurantii Maskell (Hemiptera: Diaspididae), using biodegradable mesoporous pheromone dispensers
}

Published on Pest Management Science (Vacas et al, 2010)

\begin{abstract}
The control of California red scale (Aonidiella aurantii Maskell) has encountered many difficulties, which have raised interest in alternative control methods. Up to now, the $A$. aurantii sex pheromone has been used only for monitoring. In a previous work we have described a biodegradable mesoporous pheromone dispenser for mating disruption. To verify the efficacy of these dispensers, three field trials were conducted and the results are shown in this paper. The study of the release profile of these dispensers revealed a mean pheromone emission value of $269 \mu \mathrm{g} \mathrm{day}^{-1}$ and levels of residual pheromone of $10 \%$ at the end of 250 days. During the $2^{\text {nd }}$ flight, an $A$. aurantii male catch reduction of $98 \%$ was achieved in the mating disruption plot of trial $1,93.5 \%$ in trial 2 and $76.7 \%$ in trial 3. During the $3^{\text {rd }}$ flight, reductions were $94.1,82.9$ and $68.1 \%$ in trials 1,2 and 3 respectively. Considering damaged fruit with more than 5 scales, it was obtained a reduction of about $80 \%$ and $60 \%$ in the mating disruption plot of trial 2 and 3 respectively compared to an untreated plot, and a reduction of about $70 \%$ in trial 1 compared to an oil treated plot. Mating disruption has been found to be an efficient technique to control this pest, working equally well as a correctly sprayed oil treatment. Further studies are needed to improve the determination of the time of the dispensers' application and evaluate the effects of the pheromone on natural enemies.
\end{abstract}




\section{II.1 Introduction}

Worldwide citrus orchards are greatly affected by diaspidid pests, specially Aonidiella aurantii (Maskell), known as California red scale (CRS), which is listed as the most important species causing economic damage and crop losses, to whom its life cycle has been extensively studied (Tashiro and Beavers, 1968; Kennet and Hoffmann, 1985; Koteja, 1990; University of California, 1991). Adult male emergence coincides with the development of third instar females (virgin females) (Tashiro and Beavers, 1968; Kennet and Hoffmann, 1985; University of California, 1991), which then mate and produce the next generation. Virgin females attract males by releasing a pheromone, and then males may crawl to nearby females or fly to other trees (Koteja, 1990; University of California, 1991). The number of generations of CRS that could develop in citrus ranges from three to five and it is influenced by temperature (Kennet and Hoffmann, 1985; Grout et al., 1989). Under the climatic conditions of Spanish citrus areas, CRS shows three complete generations with three male flights, the first of which takes place between mid-April and mid-May, the second between mid-June and late July and the third from mid-August to late-September, with little variation between regions. Cosmetic damage caused by this armoured scale leads to downgrading or rejection of the fruit at the packing house. Moreover, heavy scale infestations may lead to yellowing of leaves, defoliation, branch dieback and possible tree death (GraftonCardwell and Reagan, 1995).

The economic importance of this armoured scale is due to the fruit damage, the cost of the management tools to defeat it, as well as the difficulty in efficiently applying insecticide treatments. Traditional chemical control for CRS has been affected by the development of resistances to insecticides, including fumigation with hydrocyanic acid $(\mathrm{HCN})$ in the beginning of the last century (Yust et al., 1943a,b), and the use of organophosphate and carbamate insecticides (Collins et al., 1994; Grafton-Cardwell and Vehrs, 1995; Grafton-Cardwell et al., 1998). Consequently, growers have had to rely on new integrated and biological control programs. The use of mineral oils appeared to be a good alternative to 
conventional pesticides, having low residual toxicity for beneficial insects. But these can potentially be phytotoxic (Grafton-Cardwell and Reagan, 1995; Tan et al., 2005), requiring certain precautions to avoid negative effects and to ensure the efficacy of the spray. Moreover, oil treatments require an accurate determination of the timing of the treatment, to be applied when the target pest is in its most vulnerable $1^{\text {st }}$ instar stage (University of California, 1991). The use of insect growth regulators (IGR) such as buprofezin (Yarom et al., 1988; Grout and Richards, 1991a; Ishaaya et al., 1992) and pyriproxyfen (Alfaro et al., 1999b; GraftonCardwell et al., 2006; Eliahu et al., 2007; Rill et al., 2007), provided an important alternative to replace traditional insecticides. These IGR were classified as reduced risk insecticides, but their role in the conservation of some natural enemies groups was dubious (Grafton-Cardwell and Gu, 2003; Grafton-Cardwell et al., 2006; Lauziere and Elzen, 2007). Augmentative releases of the aphelinid parasitoid Aphytis melinus DeBach are competitive with conventional insecticide treatments in California (Moreno and Luck, 1992), South Africa (Bedford, 1996), and Australia (Furness et al., 1983). A. melinus was introduced into the citrus-growing region of Eastern Spain in 1976 from Antibes (France) (Rodrigo et al., 1996; Pina and Verdú, 2007). Since then, it has been mass-reared at the Insectary of the Plant Protection Service in Almazora, (Castellón, Spain), and released in several areas of the Valencian Community (region of Eastern Spain). Rodrigo et al., in 1996, published that these parasitoids did not provide an economic level of control of the pest. CRS control by augmentative releases of this parasitoid is currently under study in Spain. Sorribas et al., indicated in 2008 that augmentative releases of Aphytis sp. could be helpful to the naturally-occurring parasitism. On the other hand, its effectiveness depends on careful monitoring, in order to establish the exact release date and the use of selective insecticides for other pests which do not affect natural enemies.

The production of sex pheromone was demonstrated in CRS years before the chemical structures were reported by Roelofs et al. in 1977 (Tashiro and Chambers, 1967; Roelofs et al, 1977). Since then, synthetic sex pheromone traps have been widely employed as a management and detection tool for CRS populations (Moreno et al, 1972; Gradner et al., 1983; Kennet and Hoffmann, 
Capítulo II

1985; Moreno and Kennet, 1985; Samways, 1988; Grout et al., 1989; Grout and Richards, 1991b). The CRS sex pheromone was described as 3-methyl-6isopropenyl-9-decen-1-yl acetate (I) and (Z)-3-methyl-6-isopropenyl-3,9-decadien1 -yl acetate (II) (Roelofs et al, 1977). All possible geometrical and optical isomers of the two compounds were synthesized and tested by Gieselmann in 1980. The results showed that only one isomer of each compound was significantly more active: $(3 S, 6 R)-I$ and $(3 Z-6 R)-I I$ and the presence of other isomers in the mixture had no effect on trap catches (Tashiro et al., 1979; Gieselmann et al., 1980). These findings may lead to the development of new methods of control based on pheromones, such as mating disruption. Some researchers attempted to perform mating disruption for CRS using rubber pheromone dispensers. The results showed a male catch reduction, but the effectiveness of the technique was not clearly demonstrated (Barzakay et al., 1986; Hefetz et al., 1988). However, a new mesoporous pheromone dispenser was described in a previous work (Vacas et al., 2009a). In the current study, the duration and efficacy of mesoporous mating disruption dispensers to control $A$. aurantii were verified in three citrus orchards in Spain. The mating disruption treatment was compared with untreated plots, oil treatments and the combination of mating disruption+oil spray. This paper describes the first effective mating disruption treatment against a diaspidid pest.

\section{II.2 Material and Methods}

\section{II.2.1 Mesoporous dispenser and device}

Mesoporous dispensers are cylindrical tablets $9 \mathrm{~mm}$ in diameter and 10 $\mathrm{mm}$ in length, made of a mesoporous material (Corma et al., 1999, 2000). The initial load of dispensers was $50 \mathrm{mg}$ (a.i) of the CRS sex pheromone, and the formulation contained the diastereomeric mixture $(3 S, 6 R$ and $3 S, 6 S)$ of the 3 methyl-6-isopropenyl-9-decen-1-yl acetate (74\% of purity). This mixture was supplied by Ecología y Protección Agrícola (Valencia, Spain).

Dispensers were hung inside polypropylene (PP) baskets, supplied by Ecología y Protección Agrícola. The PP baskets are $50 \mathrm{~mm}$ wide and $90 \mathrm{~mm}$ in 
length. The pheromone is released through a $6 \times 5 \mathrm{~mm}$ mesh. The pheromone basket has a hanger at the top for attachment to branches.

\section{II.2.2 Experimental design}

Three mating disruption trials were conducted in $>10$ years old citrus orchards, 1 trial located in Rio Tinto (Huelva, Spain) and 2 trials in Picasent (Valencia, Spain), to test the efficacy of the mesoporous mating disruption dispensers. To choose the orchards, the population level of $A$. aurantii during the previous season was monitored based on the flight of males. The maximum of male catches in Picasent was approximately 1100 males per trap per week and around 400 males per trap and week in Rio Tinto. For the mating disruption treatment, devices were hung at a height of about $2 \mathrm{~m}$, inside the tree canopy, at a density of one dispenser per tree.

Oil treatments were timed for the presence of crawlers. Plant Protection Service of the local government carried out the crawler assessments and the oil treatments timing was defined according to their data. The crawlers were monitored according to the sampling method suggested by the Valencian Community IPM program. Twenty five 2 to 3 year old infested branches were randomly sampled in each trial, each week from the date of first flight, and taken to the laboratory. Leaves and twigs were removed from those branches and they were cut into $10 \mathrm{~cm}$ long pieces. One hundred live scales were identified as first, second and third instars, adult females and adult females with crawlers, using a binocular scope. The oil treatment was applied when first and second instars represented $70 \%$ of live scales and more than $90 \%$ of adult females had crawlers. The decision to treat the $2^{\text {nd }}$ and $3^{\text {rd }}$ generation was based on the percentage of infested fruit. The treatment threshold was established in $2 \%$ of infested fruit according to Valencian Community IPM guidelines. Ten trees and 10 fruits per tree (8 outer and 2 inner) were randomly collected and the percentage of fruit with more than 3 scales was recorded. All paraffinic oil $\left(10 \mathrm{~g} \mathrm{~L}^{-1}\right.$ ) (Argenfrut RV, Gulf Oil Argentina, S.A., Argentina) applications were made with an M1500 speedsprayer 
(Marisan, Valencia, Spain) calibrated to deliver $2500-3500 \mathrm{~L} \mathrm{ha}^{-1}$ at $150 \mathrm{psi}$ with the tractor driven at $1.55 \mathrm{~km} \mathrm{~h}^{-1}$.

\section{II.2.2.1 Trial 1}

This trial was carried out in Rio Tinto (Huelva, Spain) in a navelina Citrus sinensis Osbeck orchard with trees spaced at 7 by $5 \mathrm{~m}$. It is an orchard with a steep slope, with a difference in high of almost $3 \mathrm{~m}$ between rows. The orchard was divided by roads into three plots, as follows: (1) 5 ha were treated with the combination mating disruption-oil spray (MD+Oil). (2) The second plot with 10 ha was only treated with an oil spray (Oil Control plot). (3) Inside the MD+Oil plot, 0.3 ha were left oil-free and were treated only with mating disruption (MD plot). Separation between plots was approximately $30 \mathrm{~m}$, using roads as boundaries. In this trial, it was not possible to have an untreated plot because of the high cost of the potential crop loss. MD dispensers were applied on 5 March 2008, before the beginning of the $1^{\text {st }}$ CRS male flight and they were not replaced throughout the season. Oil sprays were applied on 7 June 2008, timed for the presence of crawlers. After assessing the fruit, no more oil treatments were needed.

\section{II.2.2.2 Trial 2 and 3}

In Picasent, two trials were carried out in an organic clemenules Citrus reticulata Blanco orchard (trial 2) and a late maturing Valencia Citrus sinensis Osbeck orchard (trial 3) with trees spaced 6 by $4 \mathrm{~m}$. Both trials were designed with four plots, as follows: (1) 1.5 ha MD+Oil plot, (2) 1 ha Oil Control plot, (3) inside the MD+Oil, 0.15 ha were left oil-free as an MD plot and (4) inside the Oil Control plot, 0.15 ha were left oil-free as an untreated plot. MD dispensers were applied on 21 February 2008, before the beginning of the $1^{\text {st }}$ CRS male flight and they were not replaced throughout the season. The oil treatment was applied on 25 May, timed for the presence of crawlers. After assessing the fruit, no more oil treatments were needed. 


\section{II.2.3 Evaluation of treatment efficacy}

In order to evaluate the efficacy of mating disruption, three commercial white sticky pheromone traps (PHEROCON® $\vee$ Trap), supplied by Trécé (Oklahoma, USA), were placed across the diagonal of each plot, at least $30 \mathrm{~m}$ apart. CRS male trap catches between plots treated with pheromone and plots without pheromone dispensers were compared. Sticky traps were replaced weekly, whereas the PHEROCON® monitoring lures (Trécé, Oklahoma, USA), loaded with $250 \mu \mathrm{g}$ sex pheromone, were replaced every 42 days.

Male flights could not be monitored in the untreated plots because of their small area in trials 2 and 3 . So, oil plots were considered as control plots to compare male catches between plots with and without pheromone dispensers (mating disruption plot vs. oil plot). Therefore, traps in control plots should catch males, while in pheromone treated plots an inhibition of male catches should be observed. The absence of trap catches during mating disruption treatment is a good indication of the technique effectiveness, but crop damage assessment provides the ultimate proof (Howse, 1998). To know the percentage reduction in males captured in pheromone traps between MD and control plots, the mating disruption index (MDI) was calculated, according the following formula, $M D I=(1$ $(x / y))^{*} 100$, where $x$ was the number of males captured in MD plots and $y$ was the number of males captured in control plots. MDI for each flight was the average of the weekly MDI during the flight period.

Damage was assessed on 10 November 2008 in trial 1, 11 September 2008 in trial 2 and 6 November 2008 in trial 3. Ten trees per plot were randomly selected and evaluated for crop damage assessment. Forty fruits per tree were evaluated, with 10 fruits per orientation. The treatment threshold published in the Valencian Community IPM guidelines is 3 scales per fruit. However, fruit with up to 5 scales is generally accepted by the market (market threshold). As our goal is to test the mating disruption treatment efficacy to obtain marketable fruit, this threshold of 5 scales per fruit was employed to assess the fruit damage. However, the percentage of fruit with 1 to 5 scales was also recorded to perform a sensitivity analysis. Treatment efficacy results were given as a percentage of damaged fruit. 
In trial 1, MD efficacy was compared to the efficacy of an oil treatment and also relative to an untreated region of the orchard in trials 2 and 3.

Degree-days (Dd) were calculated according the following formula, $D d=\left(\left(T_{\max }+T_{\min }\right) / 2\right)-T_{\text {critical }}$, where $T_{\max }$ and $T_{\min }$ were the maximum and minimum temperature of the day, respectively and $\mathrm{T}_{\text {critical }}$ was considered $11.7^{\circ} \mathrm{C}$ (Kennet and Hoffmann, 1985). Temperature data were provided by the agro-climate stations of each location.

\section{II.2.4 Pheromone release profiles}

In parallel with the field trials, 40 additional dispensers were simultaneously aged over 250 days in a citrus orchard in Picasent, $500 \mathrm{~m}$ away from trials 2 and 3 . The dispensers were aged from 21 February to 2 November 2008. Residual pheromone content was extracted at different ageing times: $0,7,15,30,45,60$, 90, 120, 150, 180, 210 and 250 days, and then quantified by Gas Chromatography using a flame ionization detector (GC/FID). Three dispensers were taken from the field and analyzed in the laboratory for each ageing time period. These dispensers were extracted by solvent-extraction, at $40^{\circ} \mathrm{C}$, with a $3: 2$ methanol/dichloromethane mixture.

Red scale pheromone content was measured by GC/FID analyses (Clarus ${ }^{\circledR} 500$ gas chromatograph from PerkinElmer, Wellesley, USA) of the extracts using 1-pentanol as internal standard. All injections were made onto a ZB-5MS $(30 \times 0.25 \mathrm{~mm} \times 0.25 \mu \mathrm{m})$ column, held at $160^{\circ} \mathrm{C}$ for $5 \mathrm{~min}$ and then programmed at $2^{\circ} \mathrm{C} \mathrm{min}^{-1}$ up to $180^{\circ} \mathrm{C}$, where it was held for $1 \mathrm{~min}$, and then programmed at $45^{\circ} \mathrm{C}$ $\mathrm{min}^{-1}$ up to $250^{\circ} \mathrm{C}$. The carrier gas was helium at $1.2 \mathrm{~mL} \mathrm{~min}^{-1}$. The amounts of pheromone and the responses were connected by fitting a linear regression model, $y=a+b x$, where $y$ is the ratio between pheromone and 1-pentanol responses and $x$ is the amount of pheromone remaining in the dispensers.

Pheromone release for each dispenser type was represented by fitting an exponential model, $y=a \cdot e^{b x}$, where $y$ is the remaining pheromone load and $x$ represents the ageing days. 


\section{II.2.5 Statistical analysis}

To normalize the distributions and homogenize variance, male catches in pheromone-baited traps, per trap per week, were transformed by $\log (\mathrm{N}+1)$ before analysis of variance (ANOVA) using data from the period belonging to the $2^{\text {nd }}$ flight (from 25 June to 13 August in trial 1 and from 19 June to 14 August in trials 2 and 3 ) and $3^{\text {rd }}$ flight (from 20 August to 5 November in trial 1 and from 21 August to 8 October in trials 2 and 3 ). An LSD test at $P=0.05$ was used to assess the significance of differences in male captures among plots treated with pheromone and those without.

In order to test for significant differences in percentages of fruit injured between treatments, a one-way ANOVA model was employed with square roottransformed data (LSD test at $P=0.05$ ). The Statgraphics 5.1 package was used for all the statistical analyses.

\section{II.3 Results}

\section{II.3.1 Efficacy trials}

\section{II.3.1.1. Male catches}

A slight first flight took place in both locations during April (Figures II.1, II.2 and II.3), from 23 April to 15 May in trial 1 (maximum 38 males per trap per week), and from 20 March to 24 April in trials 2 and 3 (maximum 9 males per trap per week). The second flight began in mid-June (19 June and 25 June, respectively), with the maximum number of males caught in mid-July. The first male catches corresponding to the third flight were obtained at the end of August and third flight ended at the beginning of October in all locations. Male catches from 14 October were considered to be a partial fourth flight, as only $194^{\circ} \mathrm{C}$ degree-day were accumulated up to December and $593^{\circ} \mathrm{C}$ degree-day are needed for the development of one generation (University of California, 1991).

Pheromone trap catches of CRS males in mating disruption plots were low throughout the entire season and differed significantly with catches obtained in their respective control plots, according to the statistical values of Table II.1. Thus, 
a male disruption effect was achieved with the mesoporous dispensers, obtaining MDI values ranging from $98.1-94.1 \%$ in trial $1,93.5-82.9 \%$ in trial 2 and $76.7-68.1 \%$ in trial 3 , for the two main flights.

From 15 August to 20 October ( $3^{\text {rd }}$ male flight), mean male catches per trap and week were increased in trials 2 and $3 \mathrm{MD}$ plots in comparison to trial $1 \mathrm{MD}$ plot. Moreover, the MDI (Table II.1) was significantly lower in trials 2 and 3 than in trial 1 during the $3^{\text {rd }}$ flight $(F=10.60$, d.f. $=2,22, P<0.01)$. Both results suggested a loss in disruption during this period in trials 2 and 3 .

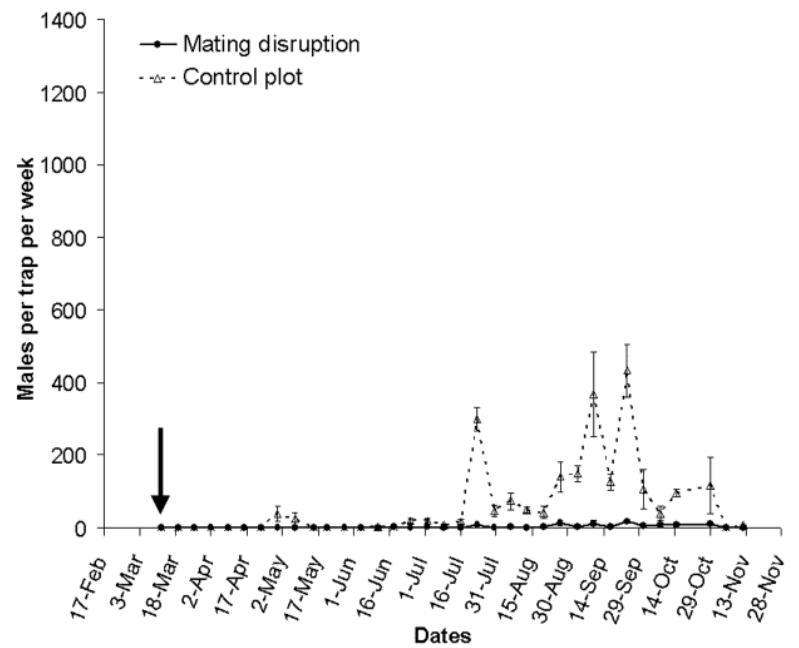

Figure II.1 Male CRS catches per trap per week, in monitoring sticky traps, for mating disruption treated plots and control plots in Trial 1 (Rio Tinto, var. Navelina). Oil plot (without pheromone dispensers) was considered as control plot. The arrow points out the date of dispensers' application. 


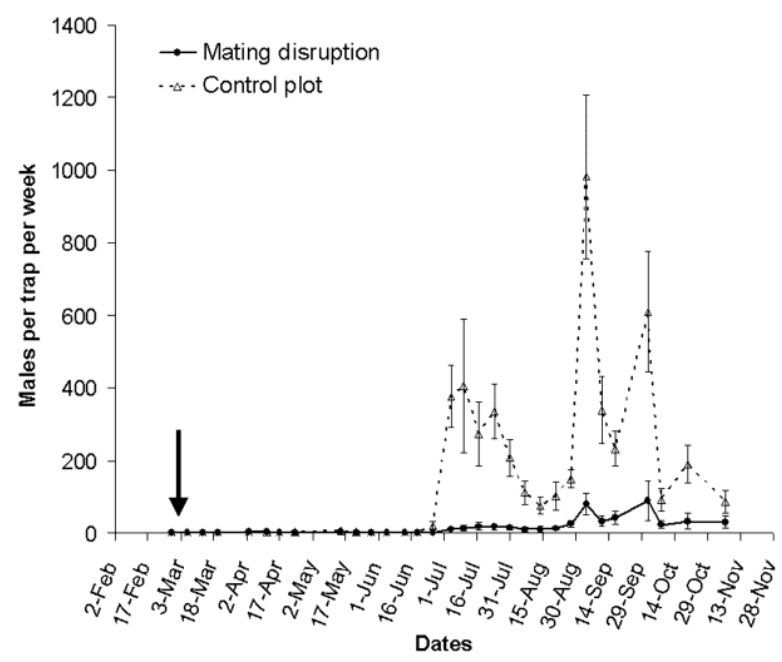

Figure II.2 Male CRS catches per trap per week, in monitoring sticky traps, for mating disruption treated plots and control plots in Trial 2 (Picasent, var. Clemenules). Oil plot (without pheromone dispensers) was considered as control plot. The arrow points out the date of dispensers' application.

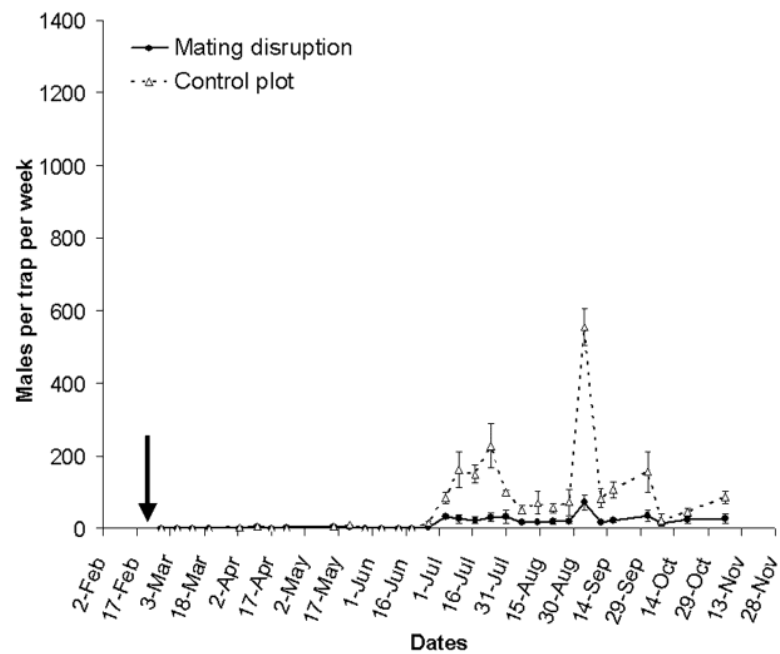

Figure II.3 Male CRS catches per trap per week, in monitoring sticky traps, for mating disruption treated plots and control plots in Trial 3 (Picasent, var. Valencia). Oil plot (without pheromone dispensers) was considered as control plot. The arrow points out the date of dispensers' application. 
Table II.1 Mean and SE males per trap per day, mating disruption index (MDI) and statistical parameters obtained by analysis of variance (ANOVA), to assess the significance of differences in total male captures among plots treated with pheromone and those without, during $2^{\text {nd }}$ and $3^{\text {rd }}$ flights. Means in a row followed by the same letter are not significantly different (ANOVA test, $P>0.05$ ). MDI explain the mean percentage reduction in male catches per flight for each trial.

\begin{tabular}{|c|c|c|c|c|c|c|c|}
\hline & & MD plot & Control plot & MDI & $F$ & DF & $P$ \\
\hline & & $\begin{array}{c}\text { Mean } \pm \\
\text { SE }\end{array}$ & Mean \pm SE & & & & \\
\hline \multirow{6}{*}{$\begin{array}{l}2^{\text {nd }} \\
\text { flight }\end{array}$} & Trial 1 & $1.36 \pm$ & $52.50 \pm$ & & 56.29 & 1,82 & $<0.001$ \\
\hline & & $0.51 \mathrm{a}$ & 12.98 b & 98.1 & & & \\
\hline & Trial 2 & $9.35 \pm$ & $180.13 \pm$ & & 36.65 & 1,68 & $<0.001$ \\
\hline & & $1.08 \mathrm{a}$ & $29.11 \mathrm{~b}$ & 93.5 & & & \\
\hline & Trial 3 & $17.69 \pm$ & $85.57 \pm$ & & 26.51 & 1,67 & $<0.001$ \\
\hline & & $2.08 \mathrm{a}$ & $13.76 \mathrm{~b}$ & 76.7 & & & \\
\hline \multirow{6}{*}{$\begin{array}{l}3^{\text {rd }} \\
\text { flight }\end{array}$} & Trial 1 & $6.82 \pm$ & $144.09 \pm$ & & 53.89 & 1,75 & $<0.001$ \\
\hline & & $1.38 \mathrm{a}$ & $23.66 \mathrm{~b}$ & 94.1 & & & \\
\hline & Trial 2 & $40.36 \pm$ & $308.96 \pm$ & & 25.70 & 1,61 & $<0.001$ \\
\hline & & $4.39 a$ & $58.11 \mathrm{~b}$ & 82.9 & & & \\
\hline & Trial 3 & $27.81 \pm$ & $114.92 \pm$ & & 7.45 & 1,60 & 0.008 \\
\hline & & $2.91 \mathrm{a}$ & $31.50 \mathrm{~b}$ & 68.1 & & & \\
\hline
\end{tabular}

\section{II.3.1.2. Fruit damage}

In trial 1 , the efficacy of the mating disruption treatment was checked relative to the efficacy of an oil treatment (Figure II.4). No significant differences were found between treatments for 1 to 5 scales $(F=1.58$, d. $f=2,26, P=0.226)$. But the percentage of fruit with $>5$ scales was significantly reduced in MD and MD+Oil plots (less than $7 \%$ damaged fruit), compared to $20 \%$ scale-infested fruit in the Oil control plot with no significant differences between the MD and MD+Oil plots 
$(F=12.31$, d. $f=2,26, P<0.001)$. If we focus on trial 2 results (Figure II.5), significant differences were observed between the percentage of fruit with 1 to 5 scales $(F=9.06$, d. $f=3,41, P<0.001)$. But for $>5$ scales per fruit damage was highly reduced in MD plot (less than $10 \%$ damage), compared to the $45 \%$ of fruit with $>5$ scales in the untreated plot. In trial 2, there were no significant differences between $M D$ and oil control plots. The best results were obtained with the combination of mating disruption and oil treatment, applied in the first generation, for this early variety of citrus $(\mathrm{F}=24.18$, d. $\mathrm{f}=3,41, \mathrm{P}<0.001)$. In trial 3 (Figure II.6), significant differences in fruit injured with 1 to 5 scales were observed between the combination $\mathrm{MD}+\mathrm{O}$ il and the untreated plot $(\mathrm{F}=1.97$, d. $\mathrm{f}=3,36, \mathrm{P}=0.138)$. In addition, damage assessment in trial 3 , showed that any of these treatments was effective in reducing damage compared to the untreated plot $(F=8.79$, d. $f=3,36$, $\mathrm{P}<0.001)$ when the threshold of more than 5 scales was set, although assessment was performed long before harvest and this time may have allowed the development of a new CRS generation on fruit.

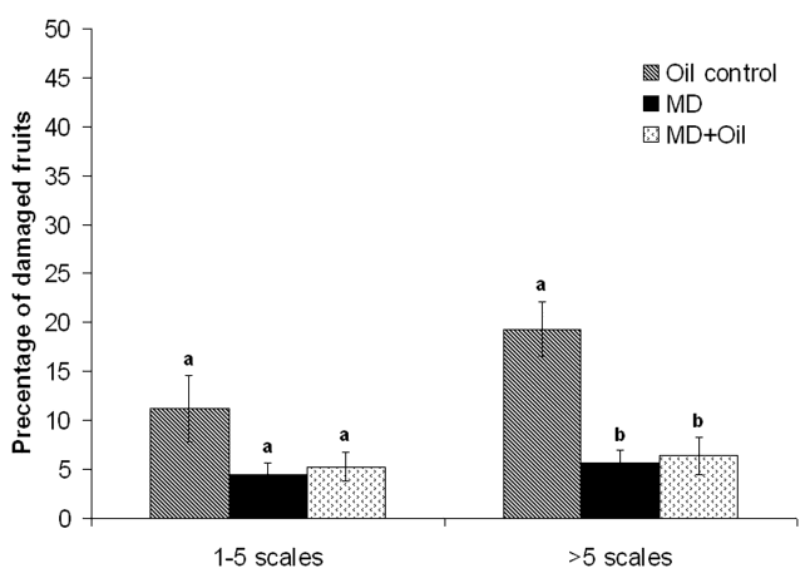

Figure II.4 Mean percentage of damaged fruits observed inside the different plots: oil control, mating disruption $(\mathrm{MD})$ and $\mathrm{MD}+$ oil treatment, for Trial 1 (Rio Tinto, var. Navelina). Bars labelled with the same letter do not differ significantly (ANOVA test, $P>0.05$ ) 


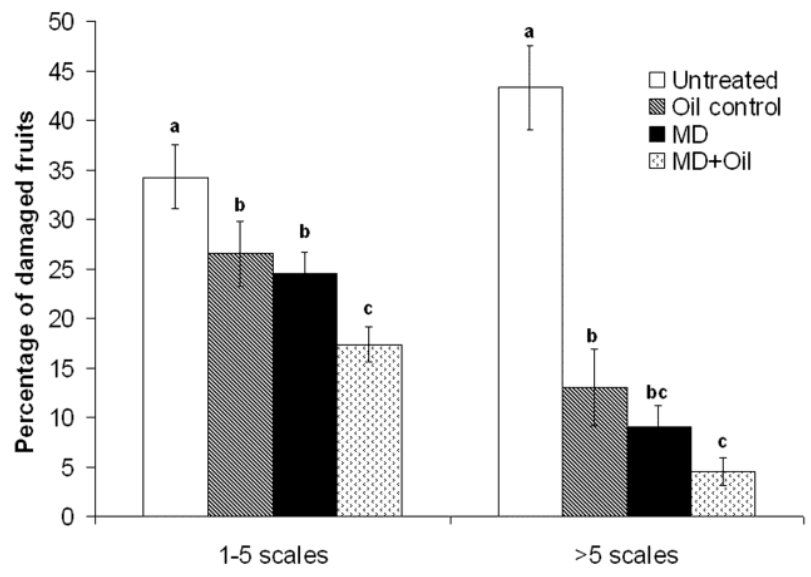

Figure II.5 Mean percentage of damaged fruits observed inside the different plots: untreated, oil control, mating disruption (MD) and MD+oil treatment, for Trial 2 (Picasent, var. Clemenules). Bars labelled with the same letter do not differ significantly (ANOVA test, $P>0.05$ )

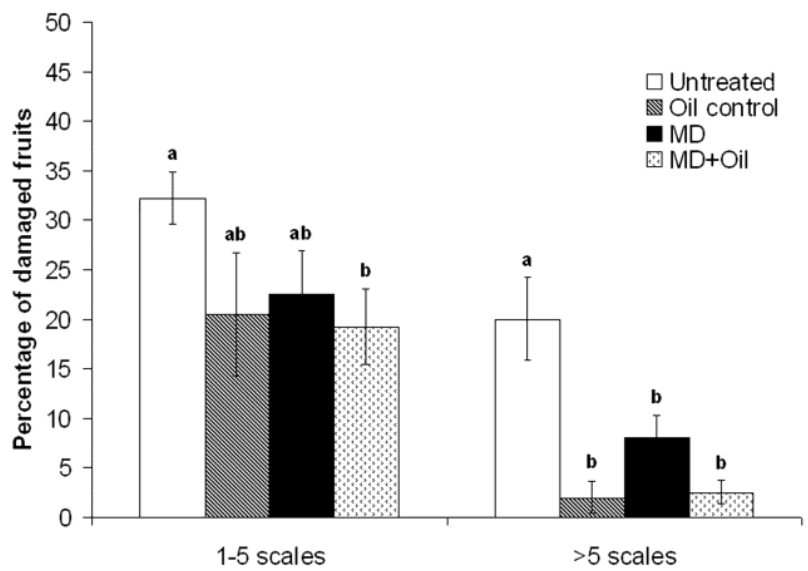

Figure II.6 Mean percentage of damaged fruits observed inside the different plots: untreated, oil control, mating disruption (MD) and MD+oil treatment, for Trial 3 (Picasent, var. Valencia). Bars labelled with the same letter do not differ significantly (ANOVA test, $P>0.05$ ) 


\section{II.3.2. Pheromone release profiles}

Figure II.7 shows the residual pheromone versus time for the mesoporous dispensers. The residual pheromone load fits the exponential model $y=49,668 \cdot e^{-0,0087 x}$, resulting $R^{2}=0.98$. This study also showed that the mesoporous dispenser emitted approximately $90 \%$ of its pheromone load during the test period. The low content of residual pheromone in the dispenser is a key parameter for the cost of the treatment.

The mean amount of pheromone emitted per day from this dispenser was $269 \mu \mathrm{g} \mathrm{day}{ }^{-1}$. This value is consistent with data published by our group, determining the minimum mean release value $\left(>250 \mu \mathrm{g} \mathrm{day}^{-1}\right)$ to obtain disruption effect in CRS males (Vacas et al, 2009a). This mesoporous dispenser has a regular pheromone release during the first 150 days, which decreases significantly from that moment on.

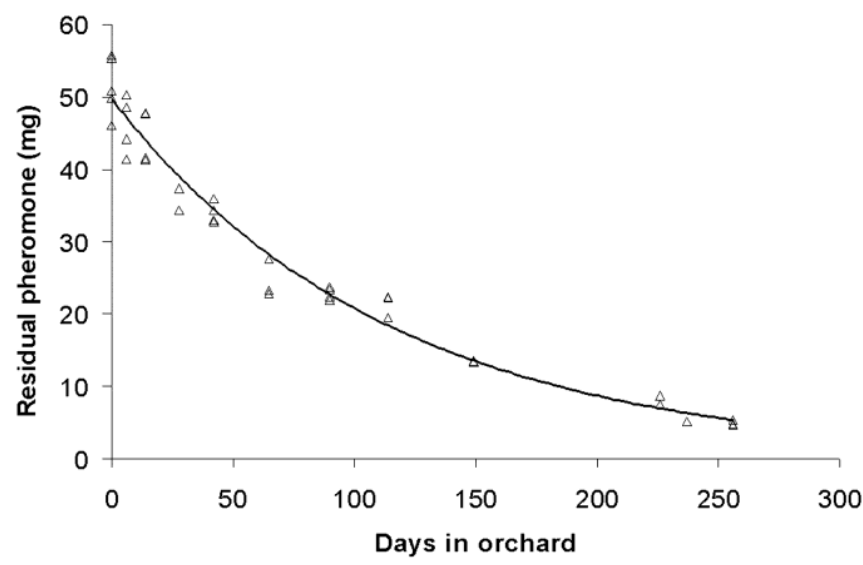

Figure II.7 Relationship between the remaining amount of pheromone in the mesoporous dispensers $(\mathrm{mg})$ and the corresponding days of field exposure. Signification of the exponential model was $R^{2}=0.98$. 


\section{II.4 Discussion}

The level of male CRS captures in trials 2 and 3 MD plots increased significantly in September in comparison with trial 1, with lower MDI values during the $3^{\text {rd }}$ flight (September-October) in trials 2 and 3 . This could be due to the pheromone application, which was dispensed 2 weeks earlier in trials 2 and 3 . Comparing this increase of captures to the pheromone release profile, this period coincides with the end of the life-span of these dispensers, which is 6 months (mean pheromone release rate $<250 \mu$ day $^{-1}$ ) (Vacas et al., 2009a). These results indicated that after 6 months of field application, the disruption effect decreased because the emission of pheromone was not high enough to disrupt the CRS $3^{\text {rd }}$ flight. Not considering the pheromone release profile, this increase of captures could be attributed to higher density of scales at that time of year. However, results of damage assessment showed that the percentage of damaged fruit was significantly lower in MD plot compared to an untreated plot. This means that the disruption effect took place and therefore a higher density of scales was not likely before September. Additional trials are needed to adjust the timing of dispenser application and promote pheromone release until the CRS generational cycles are completed. This research could alter the date of application of the dispensers or suggest a higher pheromone dosage. But the increase of the pheromone load has some drawbacks, because the pheromone represents approximately the $95 \%$ of the price of the dispenser.

Our results in trials 2 and 3 showed that any of the control methods employed in these trials was effective against CRS compared to an untreated plot. We have found that mating disruption treatment alone could reduce damage of $A$. aurantii in fruit by 80 and $60 \%$ in trials 2 and 3, respectively. Also, trials 2 and 3 demonstrated that mating disruption worked equally well as a correctly sprayed oil treatment. Correct timing of the oil application, a good calibration of the sprayer and a good coverage of all the above-ground parts of the tree are key factors to ensure the efficacy of the treatment. The fruit injury obtained in Oil plot of trial 1 was significantly higher than in MD plot, which was not the case in trials 2 and 3 . As the timing of the oil application was well defined in concordance with the 
number of crawlers, the low efficacy of oil treatment in trial 1 could be explained by the particular slope of Rio Tinto orchard.

CRS is widely distributed and, although the host susceptibility is related to the number of oil glands in the leaves (McClure, 1990; Asplanato and García-Marí, 1998), all citrus varieties are sensitive to its attack. According to this, our trials showed satisfactory results for mid-season varieties during the life-span of the pheromone dispensers and the three CRS generations, which generally take place in Spain. For late season varieties, like Valencia oranges, it is possible that the first generation of the following year could affect the non-harvested fruit, so it should be treated with new application of pheromone dispensers before the first flight or other effective treatment.

The PP device employed was a prototype to conduct the trials. The final device should be made of a biodegradable material, which could be left in the field without threatening the environment and could be resistant to weather conditions for almost seven months.

The pheromone device is still in development, however, we have estimated that the cost of this treatment will be approximately $200 € \mathrm{ha}^{-1}$, which is economically competitive with a conventional oil spray ( $266 € \mathrm{ha}^{-1}$ including oil and speedsprayer). In addition, in a mating disruption treatment, an accurate determination of the moment of application is not necessary, while for an oil treatment it is essential and assumes an added cost which is not often considered.

As well as oil sprays, the majority of growers have adopted the use of IGRs as a part of integrated pest management programs. The effect of buprofezin and pyriproxyfen on life stages of natural enemies has been extensively studied and they appear to be compatible with augmentative releases of $A$. melinus (Rill et al., 2008) but they are incompatible with other agents like Rodolia cardinalis (Mulsant) (Grafton-Cardwell and Gu, 2006). It must be added that European Directives regulating the use of insecticides are becoming more and more severe. In fact, the Commission Decision of the European Communities (2008/771/EC) of 30 September 2008, concerning the non-inclusion of buprofezin in Annex I to Council Directive $91 / 414 / E E C$, states that authorizations for plant protection products 
containing buprofezin were withdrawn by 30 March 2009. So mating disruption could be a good alternative to settle this matter.

In conclusion, CRS mating disruption achieved control equal to conventional oil sprays and could provide growers with a method for controlling a key citrus pest without using insecticides. Mating disruption could also be highly conducive to conservation of natural enemies. However, it is necessary to evaluate the possible effect of a high concentration of CRS sex pheromone on the behaviour of $A$. melinus and other parasitoids and predators of $A$. aurantii, as well as the influence of the pheromone on natural enemies of other pests. In this way, we are studying the influence of the mating disruption treatment in the behaviour of some CRS parasitoids. In addition, we should consider that the reduction of a wide range of insecticide treatments, due to the implementation of mating disruption as A. aurantii control method, could potentially increase secondary pest populations. Mating disruption technique could replace the use of oil spray for CRS control, but these oil treatments could be occasionally necessary for the control of other scale pests.

\section{Acknowledgements}

We are grateful to Ernesto Machancoses and Vicente Morató (Picasent), and Antonio Caballero from Rio Tinto Fruits for facilitating study orchards and assisting with the collection of trapping data. This research has been supported by Ministerio de Ciencia y Tecnología project number AGL 2009-10725. 